\title{
A educação a distância como dispositivo de fomento às redes de cuidado em saúde
}

Simone Maineiri Paulon ${ }^{1}$ Mara Lúcia Fernandes Carneiro

\begin{abstract}
Navegar agora pra mim não é mais só preciso...
\end{abstract}
é também bem divertido!

Esta foi uma dentre muitas das expressões lançadas para partilhar com outros navegantes virtuais as turbulências vividas por trabalhadores do Sistema Único de Saúde (SUS) que começavam a protagonizar um processo de formação. Ela é expressiva da experiência de educação em saúde que aqui queremos pôr em análise por vários motivos: primeiro, pela peculiaridade do objeto a que se destina um curso de pós-graduação para formar apoiadores institucionais da Humanização da Atenção e Gestão do SUS; segundo, pelo caráter de curso-intervenção que o estruturou e, ainda, por se tratar de um per-curso cuja intensidade, abrangência e potência transformadora só puderam ser atingidas com o suporte dado pelo ambiente virtual de aprendizagem que conectou trabalhadores das sete macrorregiões do estado do Rio Grande do Sul.

O próprio tema da humanização da saúde já impõe desafios a serem trabalhados que, de alguma forma, se exacerbam na aproximação ao campo da educação. Se já soa paradoxal humanos propondo-se a humanizar outros, quando se fala em formar para esta tarefa, os ruídos podem ser ainda maiores. Tomandose, entretanto, o conceito de humanização não como um valor abstrato, mas como produção de mudanças concretas que reafirmem o valor da vida e promovam práticas sociais inclusivas e solidárias (Barros, Passos, 2005), uma nova perspectiva se abre para se pensar um processo de formação.

Isto leva a crer que compartilhar uma experiência de formação na área da saúde, que tenha se utilizado do ensino a distância como ferramenta de potencialização dos princípios de humanização do SUS, possa trazer uma contribuição ao debate da educação em saúde coletiva no Brasil.

\section{Protagonismo na educação e a formação de apoiadores da PNH ... experimentações navegantes}

Que bacana! Até aqui tudo bem, já não estou tão assustada. Sucesso a todos nós! Que tenhamos um aproveitamento maravilhoso para efetivarmos junto aos colegas e gestores as ações humanizadoras em

${ }^{1}$ Departamento de Psicologia Social, Instituto de Psicologia Social, Universidade Federal do Rio Grande do Sul (UFRGS). Av. Ramiro Barcelos, 2600. Porto Alegre, RS, Brasil. 90.035-000 simone.paulon@ufrgs.br 2 Departamento de Psicologia Social, Instituto de Psicologia Social, 
nosso município e arredores. Parece que vai rolar... Abraços calorosos a todos. (V.)

A publicação do edital nas 19 coordenadorias de saúde do Estado, que abriu as inscrições para seleção do primeiro curso de pós-graduação lato-sensu promovido pela Política Nacional de Humanização ${ }^{3}(\mathrm{PNH})$, era bem específica em relação a um requisito: todo candidato deveria ser trabalhador do SUS, atuante em alguma unidade de saúde que referendasse sua participação. Mais do que garantir a contrapartida dos municípios no financiamento dos oito encontros presenciais previstos para os dez meses de curso, o que justificava tal exigência era a necessidade de corresponsabilizar gestores locais, candidatos e equipes de trabalho com um processo de formação que implicaria a todos, por seu caráter de curso-intervenção.

A experiência não era pioneira. Inspirou-se na perspectiva adotada pela $\mathrm{PNH}$, a partir de 2006, quando promoveu o curso nacional de formação de apoiadores institucionais ${ }^{4}$. Baseava-se no entendimento dos processos de formaçãointervenção como possibilidade educativa mais afinada aos princípios do SUS, fundamentalmente em relação aos propósitos de fomentar o protagonismo dos atores do sistema e estimular a cogestão dos processos de trabalho em saúde (Heckert, Neves, 2007).

Isto se aproxima da definição pedagógica de Educação Permanente em Saúde como processos que colocam o cotidiano do trabalho em análise, instigam os coletivos à reflexão e ação e, ainda, permeiam movimentos instituintes nos serviços. Mas ao elaborar um projeto de educação extensivo, para todas as regiões do país e norteado pelo princípio da formação-intervenção, a PNH, de alguma forma, radicalizou a concepção do permanente no campo da educação em saúde, não com uma conotação meramente cronológica, de estender-se no tempo, mas como um processo formativo focado no "aqui-e-agora, diante de problemas reais, pessoas reais e equipes reais" (Ceccim, 2004, p.167).

Considerando-se, ainda, como afirma o mesmo autor,

[...] que aquilo que deve ser realmente central à Educação Permanente em Saúde é sua porosidade à realidade mutável e mutante das ações e dos serviços de saúde; é sua ligação política com a formação de perfis profissionais e de serviços, a introdução de mecanismos, espaços e temas que geram auto-análise, autogestão, implicação, mudança institucional, enfim, pensamento (disruptura com instituídos, fórmulas ou modelos) e experimentação (em contexto, em afetividade - sendo afetado pela realidade/afecção). (Ceccim, 2004, p.162)

podemos situar o projeto de formação aqui relatado neste campo de trabalho e estudos. Para avançarmos na compreensão da radicalidade com que o caráter de experimentação/produção de subjetividades se apresenta na proposta em debate, vale lembrar que o convite feito em 2006 àqueles cento e quarenta trabalhadores do SUS, distribuídos pelo Brasil afora, não era para que se inscrevessem meramente em um curso de aperfeiçoamento profissional em humanização, mas para que, além disso, desejassem se tornar "apoiadores institucionais".

A função apoio, que tem norteado os processos de formação da $\mathrm{PNH}$, foi proposta por Campos (2007) como resultante da ação de sujeitos que "atravessam" o processo de trabalho de coletivos com a finalidade de ampliar sua capacidade de acolher e resolver necessidades de saúde, bem como o grau de

\author{
${ }^{3}$ A $1^{\text {a }}$ edição do curso \\ de pós-graduação lato- \\ sensu em Humanização \\ da Gestão e Atenção do \\ SUS ocorreu entre os \\ meses de junho de 2007 \\ e abril de 2008, e foi \\ viabilizada por contrato \\ de cooperação técnico- \\ científica firmado entre o \\ Ministério da Saúde, por \\ meio da Política Nacional \\ de Humanização (PNH); a \\ Universidade Federal do \\ Rio Grande do Sul \\ (UFRGS), por meio do \\ Instituto de Psicologia; a \\ Universidade Regional do \\ Noroeste do Estado do \\ Rio Grande do Sul \\ (UNIJUI), por intermédio \\ do Departamento de \\ Ciências da Saúde; e a \\ Universidade Federal \\ Fluminense (UFF), por \\ meio do Departamento \\ de Psicologia. Esta $1^{\text {a }}$ \\ edição formou 66 \\ apoiadores e, em agosto \\ de 2008, abriu-se a $2^{\mathrm{a}}$ \\ edição, com cem vagas, \\ por meio de uma nova \\ parceria estabelecida \\ entre MS/PNH, \\ Secretaria de Saúde do \\ Estado do RS/Escola de \\ Saúde Pública e Instituto \\ de Psicologia da UFRGS. \\ ${ }^{4}$ Trata-se do curso de \\ aperfeiçoamento para \\ formação de Apoiadores \\ da Política Nacional de \\ Humanização da Atenção \\ e Gestão do SUS, \\ promovido entre abril e \\ dezembro de 2006, pela \\ parceria de cooperação \\ técnica entre Ministério \\ da Saúde/SAS/PNH, UFF \\ e FIOCRUZ/ENSP/EAD, \\ que disponibilizou cento \\ e quarenta vagas, \\ distribuídas em todo \\ território nacional. Os \\ textos de Passos e Barros \\ (2006) e de Heckert e \\ Neves (2007), referidos \\ adiante, debatem esta \\ experiência específica de \\ formação.
}


${ }^{5}$ A discussão mais aprofundada desses princípios, seus desdobramentos em eixos e dispositivos de ação, bem como sua contextualização no atual cenário do SUS encontrase no artigo de Pasche (2009) neste mesmo suplemento.

${ }^{6}$ As bases da Política de Formação e Pesquisa da $\mathrm{PNH}$ foram elaboradas e validadas pelo coletivo de consultores e por meio de diferentes processos de formação ocorridos ao longo dos anos de 2006 2008, sob coordenação dos professores Eduardo Passos e Ana Heckert, e resultaram em documento-fonte das informações acima citadas, em fase de publicação pelo Ministério da Saúde.

${ }^{7}$ Para detalhamentos da concepção de avaliação que orienta as ações da $\mathrm{PNH}$, consultar Santos Filho (2007). realização dos trabalhadores com suas atividades, seus grupos e formas de organização dos serviços, tornando-os mais democráticos e criativos.

Por isso, ao se sentirem convocados pelo objetivo de "compreenderem a complexa dinâmica da produção da tríade saúde-doença-atenção e intervir sobre problemas de gestão dos serviços e processos de trabalho em saúde com soluções criativas" (Passos, Barros, 2006), os candidatos às formações que a PNH tem ofertado já estão desafiados a se deslocarem da cômoda posição de alunos para assumirem um lugar de protagonismo na própria formação.

Esta perspectiva permitiu à PNH apostar fortemente na possibilidade de um processo educativo potencializar os efeitos norteadores de uma política pública. Mas estes não seriam efeitos quaisquer, já que, nos princípios da própria Política promotora desta formação, estão: a inseparabilidade da atenção e gestão, a transversalidade dos processos comunicativos, e o protagonismo dos sujeitos ${ }^{5}$. Como formar protagonistas? Há uma pedagogia da solidariedade, que instigue à grupalidade? É possível (re)educar cidadãos para que se compreendam gestores dos próprios processos de trabalho de que se sentem, em geral, expropriados? Tendo questões de tamanha densidade em seu horizonte é que estas primeiras investidas extensivas da $\mathrm{PNH}$ em formação resultaram na elaboração de uma Política de Formação ${ }^{6}$ que, entre outros objetivos, se destina a amplificar a abrangência do "modo de fazer" humanizado em saúde, integrando novos atores aos processos de formação-intervenção. Ela é calcada nos seguintes princípios:

1 Inseparabilidade entre formar e intervir: as ações são dispositivos de problematização da experiência de trabalho em saúde; toda formação se delineia em torno de um plano de intervenção que se destina, sempre, à ampliação dos modos de comunicação dos coletivos e de compartilhamento de experiências concretamente vividas nos serviços;

2 Foco no "Aprender-fazendo": Não importa tanto o "fazer conhecer" quanto o "fazer participar" da Política, estabelecendo-se aí uma outra relação com o aprender em termos de apropriação, mobilização e construção de conhecimentos.

3 Descentralização e corresponsabilização locais: A formação é alinhavada a partir de uma fina análise do cenário em que se inscreve, de forma a garantir que sejam projetos compartilhados e pactuados com o maior número possível de atores das regiões a que se destinam, incluindo sempre novos atores estratégicos;

4 Avaliação Formativa7: Incentivam-se os cursos a incluírem a identificação e incorporação dos "analisadores institucionais" que o processo for produzindo em suas metodologias a fim de enfatizar o caráter participativo e emancipatório que a avaliação pode assumir.

A aposta, portanto, na potência de um processo de formação para produção de um novo cuidado em saúde sustenta-se em determinadas escolhas éticopolíticas que justificam escolhas metodológicas afinadas aos princípios do SUS. Transformar práticas profissionais fragmentárias em modos de cuidar pautados pela universalidade, participação e integralidade da saúde, hoje garantidos em lei a todo cidadão brasileiro, requer esforços instituintes não apenas no campo da saúde. Há que se transformar também, profundamente, as práticas educacionais dirigidas aos profissionais de saúde, estruturadas, geralmente, no sentido clássico da transmissão de conhecimentos técnico-científicos a serem aplicados em dada realidade. Formação no sentido aqui referido diz respeito à produção concomitante de conhecimentos, sujeitos e realidades. Diz respeito à transformação do mundo numa morada - ethos que acolha a diversidade da vida e referende as muitas saúdes possíveis.

Estamos, pois, afirmando a proposta de formação-intervenção como uma prática ético-política, que extrapola a clássica oferta de conhecimentos de dada 
profissão e que aprofunda os propósitos da educação permanente, na medida em que, além de se inserir nos problemas reais dos serviços de saúde, propõe-se a interferir nos modos de subjetivação daqueles que os habitam, produzindo, com isso, novas formas de ação. Isto permite definir formação como constituição de modos de existência, como afirmam Heckert e Neves (2007, p.154): "É neste campo de imersão que a formação ganha consistência de intervenção, de intervir entre ações, experimentando os desafios cotidianos de materialização dos princípios do SUS e da invenção de novos territórios existenciais".

Veremos, agora, de que forma a educação a distância (EAD) pode contribuir com a realização destes princípios, detendo-nos na experiência específica de formação de apoiadores institucionais realizada no Rio Grande do Sul.

\title{
A educação a distância na formação-intervenção
}

\author{
Este curso está sendo uma novidade para mim: ambiente virtual, cadastrar senhas, entrar em fóruns, \\ enviar tarefas, agendar chats ... Ufa, chega a dar um cansaço! Mas aos poucos a gente se acostuma \\ (espero) e tudo acaba dando certo. Tenho a sensação de que além de meu crescimento esta \\ experiência vai ajudar meus colegas do hospital e até da região. (F.)
}

Este depoimento inaugural de um novato na $E A D$, compartilhando sua ambiguidade frente ao primeiro contato com o ambiente em que iria conviver por quase um ano, representa uma boa expressão do que desperta a experiência de aprendizagem a distância.

Quando nos referimos, acima, à intensidade, abrangência e potência transformadora que o EAD permitiu à experiência daquele grupo de trabalhadores/apoiadores, não atribuímos, obviamente, a capacidade de produzir tais efeitos a um ambiente virtual de aprendizagem ou a um suporte tecnológico qualquer. Compartilhamos, com alguns dos pensadores da inteligência coletiva (Parente, 2004; Lèvy, 1996), a posição de que não são os instrumentos tecnológicos, mas os processos de subjetivação que eles põem em movimento que promovem novos encontros e imprimem uma nova relação homemmundo. Para Lèvy (1996, p.40), "o virtual só eclode com a entrada da subjetividade humana no circuito", o que deixa claro que "o computador é, antes de tudo, um operador de informação".

De fato, ao lançarmos mão do recurso de EAD na estruturação do curso de pós-graduação em Humanização da Atenção e Gestão do SUS no RS, não tínhamos uma visão muito diferente do que usualmente se tem definido como propósitos que justificam o uso desta modalidade de educação.

A educação a distância foi, inicialmente, definida muito mais pelas diferenças em relação à educação presencial do que pelas características que a determinam ou pelos elementos que a constituem, o que limita a compreensão de suas potencialidades.

Os benefícios e desafios que a ferramenta EAD oferece às novas formas de aprender parecem estar, ainda, muito restritos à idéia de prestação de serviços em educação para grandes contingentes de pessoas, buscando assegurar o acesso à educação por meio do uso de recursos tecnológicos, mas sem referenciar ou destacar alguma preocupação com o tipo de produção de conhecimento, a aproximação entre as pessoas ou a constituição de comunidades de aprendizagem.

A abrangência cada vez maior, em termos geográficos e de camadas populacionais, que a utilização da rede de comunicação digital pode oferecer à formação justifica tanto a popularização da $E A D$, quanto boa parte das críticas que a ela têm sido dirigidas: de superficialidade e inconsistência - equivalentes aos preconceitos que as precursoras versões dos "cursos por correspondência" sofriam.

Realmente, a possibilidade de manter em permanente contato os alunos/apoiadores de 49 municípios do RS, entre os encontros presenciais mensais que estruturavam o curso, por si só justificava a utilização do suporte proporcionado pelo ambiente virtual adotado. Mas os primeiros movimentos dos trabalhadores que voltavam a suas unidades de saúde, após dois dias de trocas intensivas nos encontros presenciais com outros trabalhadores e professores inseridos no SUS, logo indicaram que o ambiente virtual teria outra dimensão naquele percurso. 
Bueno colegas tô começando a me aventurar nesta nova (pra mim) maneira de estudar! Até q este Teleduc não é um bicho d sete cabeças, tô conseguindo navegar neste mar sem me afogar, acho q vai ser uma experiência e tanto... que bom saber que vou sentar aqui e poder compartilhar com tantos parceiros que devem estar vivendo e sentindo coisas parecidas com as minhas. Bah! Chega a dar um gaz. bjs. (E.)

EAD é um processo educativo sistemático e organizado que exige não somente múltiplas vias de comunicação entre os participantes do processo, como também a instauração de uma certa grupalidade. A escolha de determinado artefato tecnológico é, então, efeito, e não causa, como simplificadamente poderia se pensar, do projeto político-pedagógico que justifica a criação de um dado processo educativo.

No caso de um curso-intervenção com objetivo de formar apoiadores institucionais de uma política pública, que tem como propósito reencantar os princípios do SUS, fica ainda mais evidente a relevância e delicadeza que esta escolha metodológica supõe. Como ressalta o coordenador da $\mathrm{PNH}$, em recente entrevista:

\footnotetext{
${ }^{8}$ Ambiente virtual gratuito, criado pela equipe do Núcleo de Informática na Educação da Unicamp.
}

9 O fantasma da substituição do professor pelas tecnologias de comunicação, com consequente objetificação dos alunos, ainda figura em meios educacionais e se assenta em definições do EAD como a que segue: "É uma forma de educação onde são utilizados recursos

tecnológicos com a finalidade de divulgar o conhecimento para as pessoas que se encontram com barreiras intransponíveis na Educação

Convencional, seja pela impossibilidade de deslocar, seja por um grande distância geográfica, também pela limitação de tempo ou mesmo pelos seus recursos

financeiros resumidos.

É a forma mais fácil de eliminar a presença física de professor e o aluno."

(Laranjeiras Filho,
A PNH aposta na democratização das relações, pois entende ser necessária a construção coletiva de novos modos de produção subjetiva, de novos sujeitos que sejam mais capazes de se corresponsabilizarem. Para isto a PNH não propõe receitas nem prescrições, mas um método: colocar as pessoas em roda, ao lado, para coconstruírem juntas. (Pasche, 2009)

Coconstruções, experimentações coletivas, cogestão do próprio processo de formação refletiam-se nas constantes trocas encontradas nos murais, fóruns e correio do Teleduc ${ }^{8}$. Compartilhemos uma delas:

Meu Deus! Onde eu fui me meter! Que frio na barriga! Fui em uma reunião com colegas do hospital, e minha chefe colocou suas expectativas pro meu projeto de intervenção na humanização! E agora?! O que eu faço?! tutora, colegas, vcs vão ter que me ajudar muuuiito! Mas tô tri a fim de matar no peito e chutar em gol! (M.)

Pode-se perceber que, para além da eliminação das barreiras geográficas, as propostas pedagógicas com EAD não se restringem a transmitir conhecimentos, mas apoiar o estudante a aprender a aprender e aprender a fazer, de forma flexível, forjando sua autonomia em relação ao espaço, tempo, ritmo e método de aprendizagem. Esta experiência de aprendizagem-protagonista reflete-se, também, na cogestão de todo processo educativo, já que EAD exige sempre um maior grau de planejamento que o ensino presencial e amplia participação em diferentes coletivos: os participantes se apoiam uns nos outros, construindo verdadeiras comunidades de aprendizagem; intensifica-se o diálogo professor-tutor/alunosapoiadores, coordenação/professor-tutor, coordenação/alunos-apoiadores, enfim, democratização dos espaços de ensino e gestão.

As clássicas definições de EAD reforçando a transposição de barreiras geográficas, otimização do tempo ou, mesmo, a prescindibilidade da relação professor-aluno ${ }^{9}$ tornam-se um tanto quanto reducionistas quando adentramos um processo de formação como o que aqui acompanhamos. 
Na mesma linha crítica, Nevado (2004) argumenta que, sem promover maiores reflexões acerca dos fundamentos da EAD, os recursos digitais de informação têm sido utilizados apenas para transposição de estruturas clássicas de ensino a novos suportes, o que tem "favorecido as pseudoinovações, reduzindo as novas possibilidades abertas pelo uso das tecnologias à simples otimização das práticas tradicionais" (p.76).

Neste sentido, podemos afirmar que a concepção da EAD no curso (e em curso!) em debate situa-se dentro de uma tendência que vem se delineando neste campo educacional, caracterizando-se pela crítica à supremacia do tecnológico ao político-pedagógico e, a partir dela, pela disposição ao diálogo interdisciplinar, cada vez mais demandado pelas práticas educativas contemporâneas.

Entendendo que o aumento do grau de transversalidade na ação cotidiana dos serviços e das práticas de saúde, tal como inscrito nos princípios da PNH, implica mais do que simplesmente pôr as pessoas em contato, a comunicação em rede aqui ressaltada destina-se a promover antes deslocamentos subjetivos do que suprimir meros deslocamentos geográficos. Queremos, com isto, destacar que os debates on line permitidos pelo uso da EAD, a agilização das diferentes formas de encontro, a ampliação dos recursos de estudo e construções coletivas, que não ocorreriam nos esparsos encontros presenciais, permitiram tal circulação de saberes, poderes e afetos que, longe de homogeneizar a experiência de formação discutida, outorgaram um novo sentido à função de partícipes de uma política pública que aqueles trabalhadores tinham até então.

Dois aspectos movimentados pelo curso podem, ainda, ressaltar o suporte oferecido pela comunicação em rede para a intensificação do protagonismo dos sujeitos e exacerbação da dimensão do coletivo nos processos de produção de saúde: a promoção da grupalidade e o fomento às redes de cuidado.

\section{Unidades de produção conectadas e promoção de grupalidade}

Um dos estranhamentos que a estrutura pedagógica do curso de especialização em Humanização da atenção e gestão do SUS causava às instâncias acadêmicas que o aprovaram, e mesmo aos alunos candidatos, dizia respeito à organização dos grupos nas regiões em que se distribuíram por Unidades de Produção.

À primeira vista associada a uma lógica produtivista de bens e mercadoria, a unidade de produção soaria mesmo contraditória a um projeto político que não entende a gestão dos processos de trabalho em saúde como tarefa administrativa separada das práticas de cuidado. Vale, entretanto, lembrar que a formação para a função apoio tem, como tarefa primordial, fortalecer os coletivos no próprio exercício da produção de novos sujeitos em processos de mudança. Reforça-se, com isso, a tese defendida por Campos (1994), de que as possibilidades e limites da produção de mudança em saúde devem partir da "reforma dos sujeitos", ou seja, de que não existe mudança na gestão e organização dos serviços e práticas de saúde que possa prescindir da própria mudança dos sujeitos nela engajados. Permanente engendramento de modos de subjetivação, práticas de cuidado, formas lateralizadas de gestão são o sentido que se quer destacar ao se referir aos grupos de apoiadores institucionais em formação, não por turmas de alunos, mas por Unidades de Produção.

A forma como as tecnologias digitais disponibilizadas pelo ambiente virtual de aprendizagem em uso contribuíram para corresponsabilizar as unidades de produção regionalizadas com a tarefa de construção coletiva do próprio grupo, seus projetos de estudo e planos de intervenção para a região,

frequentemente era indicativa do entusiasmo que crescia entre integrantes do mesmo espaço virtual.

Geeeentiii querida! PRECISO dizer prá toda minha UP que talvez o que tenhamos vivido nessas últimas semanas, entre os milhões de mensagens, textos, poesias (nossa, quanto poeta este Teleduc tem revelado !!!!) que trocamos tenha sido um momento definitivo nas nossas vivências humanizadoras. É difícil, às vezes, entrar lá na unidade [de saúde] e tentar expressar prá minha equipe tudo que ta rolando desde que entrei nesse curso. Fico louca por uma brechinha prá espiar nosso ambiente e ver quem está por aí na mesma batalha que eu e com a mesma gana prá trazer mais gente pro nosso barco. E vcs aí?!!??!?!?!?! (M.T.) 
Assim como ressaltado anteriormente - que nenhum suporte tecnológico garante por si caráter inovador ou capacidade transformadora de um projeto pedagógico - a proposição, ao grupo, de que se utilizassem das ferramentas virtuais para darem seguimento às produções teóricas e afetivas alavancadas nos encontros não estava garantida pela estrutura do curso. O que nos permite entender - reforçando as ideias de Lèvy (1996) no que tange à inteligência coletiva, ou de Campos (2007) no campo da Saúde Coletiva - que é no encontro de um projeto ético-político com um suporte tecnológico correspondente que uma nova possibilidade comunicativa pode evocar novas produções subjetivas. Nesse sentido, vale a lembrança de Parente (2004, p.93): "Uma máquina que não fosse investida de desejo e alimentada de subjetividade seria como um corpo sem vida".

Entendendo que a formação de um grupo é algo que vai muito além do encontro de pessoas com objetivos e tarefas comuns, tomamos a indissociável relação existente entre modos de formar/ aprender/intervir/subjetivar-se como fundamento constitutivo de uma certa grupalidade que as UPs iam construindo. Com Barros, aprendemos que

O grupo tomado como dispositivo, como aquilo que põe a funcionar modos de expressão de subjetividade, opera processos de desindividualização. Eis nossa via política. [...]

Ao tomar os enunciados como remetendo não a sujeitos individuais, mas a coletivos, ao percorrer os caminhos maquínicos do desejo que não se esgotam nas vivências individualizadas, o grupo dispara desconstruções dos territórios enclausurantes da subjetividade. (Barros, 2007, p. 325)

O conceito de grupo-dispositivo, forjado pela autora para referir uma vivência coletiva que se apresenta como linha de fuga às marcas tão profundas deste modo de subjetivação do indivíduo que a todos nós constitui, parecia se corporificar em muitas das mensagens que os apoiadores da PNH insistiam em compartilhar.

[...] Quero dizer a todas vocês que nunca me senti tão bem acompanhada e feliz por estar tendo a oportunidade de viver tudo isto quando muito dos colegas não conseguem mais ter tesão de encarar novas aventuras. É bom D+ poder dividir com vcs estes intensos momentos de aprendizado e de construção e saber que sempre teremos umas as outras. (A.C.)

\section{EAD como dispositivo de fomento às redes regionais de saúde}

Se cada veículo produz uma nova relação com o espaço - o espaço que se estende diante de nós não é o mesmo se dispomos de um cavalo, um carro ou um avião -, por que não aceitar as diferenças produzidas pelo novo veículo do ciberespaço? Longe de anular o espaço, as tecnologias produzem outra forma de espacialidade ou heterotopias. (Parente, 2004, p.108)

Para além, ainda, do incremento aos encontros nas Unidades de Produção que reuniam em torno de dez apoiadores por cada macrorregião do Estado, as ferramentas virtuais ofertadas no EAD funcionaram, em muitos aspectos, também como dispositivos de potencialização das intervenções disparadas pelo curso. Nesse momento do curso, os apoiadores reuniam-se em um espaço do ambiente virtual restrito ao grupo regional e tutor.

Isto facilitou, basicamente a partir da segunda metade do processo de formação, um outro tipo de grupalização que não se inscrevia nos limites geográficos delimitados pelas UPs, mas nas afinidades criadas entre apoiadores de diferentes regiões em função das aproximações de seus tipos de intervenção.

Aos apresentarem um primeiro esboço dos planos de intervenção que pretendiam desenvolver em cada uma das unidades de saúde em que atuavam, os apoiadores elegiam alguns dos dispositivos de humanização ofertados pela PNH, com base nas análises de cenários locais da saúde em suas regiões, elaborados no primeiro momento do curso. A partir de então, outra rede de conversações começou a se 
constituir e se movimentar por dentro do ambiente virtual: redes de trabalhadores do SUS de serviços de saúde assemelhados que compartilhavam as mesmas análises dos impasses que se colocam em seus processos de trabalho e tinham, com base nessa leitura, projetos afins de humanização para suas unidades de saúde. Por solicitação dos próprios alunos, no encontro presencial em que se reuniram nesta nova configuração do grupo maior, foram constituídos novos espaços específicos no Teleduc, não mais restritos aos apoiadores de uma determinada UP com seu tutor, mas de apoiadores desenvolvendo intervenções equivalentes.

Assim, a partir da metade do per-curso de estudos e experimentações provocados pela proposta da formação-intervenção em humanização do SUS, novos encontros virtuais passaram a compor o ambiente de aprendizagem. Cinco novos grupos foram constituídos pelos eixos/dispositivos de intervenção escolhidos para disparar os processos de implementação da PNH nos municípios: Acolhimento, Clínica Ampliada, Saúde do Trabalhador, Grupo de Trabalho de Humanização e Cogestão, dentro do espaço comum a todos os participantes. Cada grupo podia, assim, propor discussões "animadas" pelos desafios e alternativas que os trabalhadores iam encontrando em seus processos de implementação das mudanças requeridas para proposição dos dispositivos de humanização, ao mesmo tempo em que podiam "espiar" a discussão desenvolvida pelos demais grupos.

Pessoal, quem está negociando a classificação de risco nas portas de emergência como eu? (R.R.)

Vocês conseguem trazer os médicos da unidade pras reuniões de GTH? (S.G.)

Olhem que tri: fui à reunião do conselho municipal de saúde apresentar minha proposta de intervenção e querem que eu apresente na próxima reunião da macro-regional! (L.K.)

Essas eram algumas das trocas que permeavam os debates nos novos espaços, entre envio de textos, debates conceituais, questões pontuais que se faziam acerca de tecnologias de intervenção, e dúvidas que se esclareciam no calor do debate de um grupo que se via cada vez mais responsabilizado pelo seu fazer.

A dimensão rizomática das redes, segundo a qual "cada ponto se conecta a outro por contágio, sem hierarquia ou filiação" (Parente, 2004, p.106), parecia exacerbar-se nesses novos espaços de encontro criados pelo movimento crescente de apropriação do processo de formação por aqueles que o vivenciavam. Ao "modo de fazer" saúde instigando os coletivos a se corresponsabilizarem pelos contextos em que se inserem, acoplava-se um modo de formar que evoca, igualmente, a dimensão inventiva do trabalho e convoca à solidariedade para solução de problemas comuns.

Em artigo no qual analisa a "microfísica do vínculo" com base na observação das formas de encontro que os serviços de saúde viabilizam, Teixeira concebe as redes de trabalho em saúde como grandes redes de conversações. E avança nesta compreensão afirmando: "As redes de trabalho em saúde - essas extensíssimas redes de conversações - passam, assim, a ser pensadas como redes de trabalho afetivo, no sentido de que o essencial nelas é, de fato, a criação e a manipulação dos afetos" (Teixeira, 2004).

Se a capacidade de afetação - deixar-se tocar e querer acessar a diferença do outro - pode ser entendida como competência necessária aos processos de humanização da saúde, a composição de uma rede que faça circular afetos, saberes e poderes, como a que este curso-intervenção parece ter possibilitado, pode ser pensada como dispositivo potencializador dos princípios que sustentam e justificam a criação de uma Política Nacional de Humanização. E, neste sentido, o suporte oferecido pelo ambiente virtual teve sua contribuição.

ai, medinho! Pensar que daqui a uns dias não teremos mais estes encontros prá continuar no Teleduc?! Nem me imagino sem esta possibilidade de sair da reunião de equipe e contar prá vcs como está andando minha intervenção. Falei com a $L$ [tutora] esta semana prá gente deixar marcado os mesmos horários de chats e seguir se falando. Mas já me aliviei de saber que vou encontrar uns quantos de vcs e até uns apoiadores das outras macro lá no MentalTchê 
[encontro estadual da luta anti-manicomial]. Eu e o pessoal do CAPS vamos lá contar como está meu plano de intervenção na rede municipal de saúde mental. Vamos lá? [...] (E.G.)

O luto pela finalização do curso se projetava em necessidade de inventar novas conexões. Ao mesmo tempo em que solicitavam a permanência do ambiente virtual como garantia de possibilidade de seguirem se encontrando enquanto unidade de produção, começavam a se perceber mais como apoiadores de uma política pública e menos como alunos de um circunstancial processo de formação. Isto se refletiu vivamente no efeito "invasão da rede" que ocorreu nos primeiros dias sucessivos ao evento de encerramento do curso. Convidados a se cadastrarem na recém-inaugurada Rede HumanizaSUS (http://redehumanizasus.net/), inúmeros posts apresentando diversas intervenções em andamento a partir do curso tomaram conta da Rede que, em poucos dias, foi apresentada não só para recantos inusitados do sul do país como, também, para as possibilidades que um processo de formação oferece quando estruturado com/por/em função de um projeto coletivo. "Coronel Bicaco tem PNH!" "HumanizaSUS desfila saúde no 7 de setembro em Pejuçara- RS!"... são algumas das manchetes encontradas no blog da PNH após encerramento do curso, que dão uma pequena dimensão da perspectiva de protagonismo e continuidade de uma Política que, para fazer jus a sua definição de Pública, não poderia mesmo visar outra coisa que não se reiniciar a cada fim. Como expresso no poema labirinto de Jorge Luis Borges (2001):

Não haverá nunca porta.

Estás dentro e o alcácer abarca o universo e não tem nem anverso nem reverso nem externo nem muro nem secreto centro. não esperes que o rigor de teu caminho que teimosamente se bifurca em outro, que obstinadamente se bifurca em outro, tenha fim. [...]

\section{Colaboradores}

As autoras trabalharam conjuntamente em todas as etapas da elaboração do manuscrito.

\section{Referências}

BARROS, R.B. Grupo: a afirmação de um simulacro. Porto Alegre: Sulina/Editora da UFRGS, 2007.

BARROS, R.B.; PASSOS, E. Humanização na saúde: um novo modismo? Interface Comunic., Saude, Educ., v.9, n.17, p.389-94, 2005.

BORGES, J.L. Elogio da sombra. Porto Alegre: Editora Globo, 2001.

CECCIM, R. Educação permanente em saúde: desafio ambicioso e necessário. Interface Comunic., Saude, Educ., v.9, n.16, p.161-8, 2005.

CAMPOS, G.W.S. Saúde Paidéia. São Paulo: Hucitec, 2007.

Considerações sobre a arte e a ciência da mudança: revolução das coisas e reforma das pessoas - o caso da saúde. In: CECÍLIO, L.C.O. (Org.). Inventando a mudança na saúde. São Paulo: Hucitec, 1994. p.29-87. 
HECKERT, A.L.; NEVES, C. Modos de formar e modos de intervir: quando a formação se faz potência de produção de coletivo. In: BARROS, M.E.B.; PINHEIRO, R.; MATTOS, R.(Orgs.). Trabalho em equipe sob o eixo da integralidade: valores, saberes e práticas. Rio de Janeiro: IMS/UERJ: Cepesc/Abrasco, 2007. p.145-60.

LARANJEIRAS FILHO, E. Educação a distância: alternativa acessível para profissionais manterem-se atualizados. 2003. Disponível em: <http://www.aleitamento.com/ a_artigos>. Acesso em: 10 jan. 2009.

LÈVY, P. O que é o virtual? São Paulo: Editora 34, 1996.

NEVADO, R. Novos possíveis na formação de professores. In: FRANCO, S.K. (Org.). Informática na educação: estudos interdisciplinares. Porto Alegre: Editora da UFRGS, 2004. p.75-95.

PARENTE, A. (Org.). Tramas na rede: novas dimensões filosóficas, estéticas e políticas da comunicação. Porto Alegre: Sulina, 2004.

PASCHE, D. Humanização do SUS cresce e atinge todo o país. Entrevista. MS Informa (publicação mensal do Ministério da Saúde, ano II, edição 1, janeiro de 2009). Disponível em: <http://www.humanizasus.net>. Acesso em: 29 jan. 2009.

PASSOS, E.; BARROS, R.B. (Orgs.). Textos/Cartilhas: formação de apoiadores para a $\mathrm{PNH}$ da gestão e atenção à saúde. Rio de Janeiro: Fiocruz, 2006.

SANTOS FILHO, S.B. Perspectivas da avaliação na Política Nacional de Humanização em Saúde: aspectos conceituais e metodológicos. Cienc. Saude Coletiva, v.12, n.4, p.999-1010, 2007. Disponível em: <http://www.scielo.br/pdf/csc/v12n4/18.pdf>. Acesso em: 30 jan. 2009.

TEIXEIRA, R. As redes de trabalho afetivo e a contribuição da saúde para a emergência de uma outra concepção de público. In: RESEARCH CONFERENCE: RETHINKING "THE PUBLIC" IN PUBLIC HEALTH: NEOLIBERALISM, STRUCTURAL VIOLENCE, AND EPIDEMICS OF INEQUALITY IN LATIN AMERICA CENTER FOR IBERIAN AND LATIN AMERICAN STUDIES UNIVERSITY OF CALIFORNIA, 2004, San Diego. Workingpaper... San Diego, 2004. Disponível em: <http://www.corposem.org/rizoma/ redeafetiva.htm >. Acesso em: 15 fev. 2009. 
O artigo descreve uma experiência de formação em saúde que utiliza como suporte um ambiente virtual de aprendizagem e propõe uma análise acerca das possibilidades oferecidas pela modalidade educação a distância à formação de redes e incremento do processo de aprendizagem-protagonista. Sustentado no conceito de educação permanente em saúde, na análise institucional e nos estudos de rede, a experiência de um curso-intervenção que operou como disparador de redes de conversação permite considerar a comunicação em rede como dispositivo potencializador dos princípios balizadores da Política Nacional de Humanização (PNH).

Palavras-chave: Política Nacional de Humanização. Educação em saúde. Educação a distância. Grupos. Redes.

\section{Distance learning as a tool for encouraging healthcare networks}

This paper describes an experience of health education that used a virtual learning environment as its support. It puts forward an analysis on the possibilities offered by the distance learning method for forming networks and increasing the protagonistlearning process. Based on the concept of continuing healthcare education and on institutional analysis and network studies, this experience of an intervention course that operated as a trigger for conversation networks has made it possible to consider network communication as a tool for bringing out the potential of the guiding principals of the National Humanization Policy (PNH).

Keywords: National Humanization Policy. Healthcare education. Distance learning. Groups. Networks.

\section{La educación a distancia como dispositivo de fomento a las redes de cuidado en salud}

El artículo describe una experiencia de formación en salud que utiliza como soporte un ambiente virtual de aprendizaje y propone un análisis de las posibilidades ofrecidas por la modalidad educación a distancia a la formación de redes de incremento del proceso de aprendizaje-protagonista. Sustentado en el concepto de educación permanente en salud, en el análisis institucional y en los estudios de red, la experiencia de un cursointervención que operó como disparador de redes de conversación permite considerar la comunicación en red como dispositivo de potenciación de los principios abalizadores de la Política Nacional de Humanización (PNH).

Palabras clave: Política Nacional de Humanización. Educación en Salud. Educación a distancia. Grupos. Redes. 